\title{
Evaluative study on the learning outcomes of a year-long postgraduate training course in community geriatrics for primary care doctors
}

TP Lam ${ }^{\mathrm{a}}$ MBBS (W. Aust.), MFM (Monash), PhD (Sydney), MD (HK), FRACGP, FHKAM, FRCP (Glas)

Rudolph WM Chow ${ }^{\mathbf{b}}$ MBBS (NSW), FRACGP, FHKCFP, DOM (CUHK),

PDipCommunityGeriatrics (HK), PDipComPsychMed (HK)

KF Lam ${ }^{c} \mathrm{PhD}(\mathrm{HK})$

IM Lennox ${ }^{\mathrm{d}}$ MB, FRCP (Glas/Edin)

Felix HW Chan ${ }^{\mathrm{e}}$ MBBCh (Wales), MSc in Health Care Management (Wales),

FRCP (Ire \& Glas), FHKCP, FHKAM

Sammy LT Tsoi ${ }^{\mathrm{f}}$ MD (Manitoba), DOM (CUHK), DFM, FHKCFP, FRACGP, PdipCommunityGeriatrics (HK), PDipComPsychMed (HK)

${ }^{a}$ Professor, Family Medicine Unit, The University of Hong Kong, 161 Main Street, Ap Lei Chau, Hong Kong

${ }^{\mathrm{b}}$ Clinical Assistant Professor, Family Medicine Unit, The University of Hong Kong, 161 Main Street, Ap Lei Chau, Hong Kong

'Associate Professor, Department of Statistics and Actuarial Science, The University of Hong Kong, Pokfulam Road, Hong Kong

${ }^{\mathrm{d}}$ Consultant Geriatrician, South Glasgow University Hospitals, UK

${ }^{e}$ Consultant Geriatrician, Fung Yiu King Hospital, 9 Sandy Bay Road, Hong Kong

${ }^{f}$ Honorary Clinical Assistant Professor, Family Medicine Unit, The University of Hong Kong, 161 Main Street, Ap Lei Chau, Hong Kong

\section{Corresponding author}

Prof. T P LAM, Family Medicine Unit, Ap Lei Chau Clinic, 161 Main Street, Ap Lei Chau, Hong Kong

Tel: (852) 25185657

Fax: (852) 28147475

Email: tplam@hku.hk 


\section{ABSTRACT}

There are increasing expectations on primary care doctors to shoulder a bigger share of care for patients with common geriatric problems in the community. This study aims to examine the outcomes of a postgraduate training course in geriatrics for primary care doctors. A questionnaire developed by the research team was sent to the Course graduates (year 2001-2007). Ninety-eight replies were received with a response rate of 52.4\% (98/187). Difference in the ratings by the respondents before and after taking the Course was analysed using the nonparametric Wilcoxon signed rank test. Most respondents felt more rewarding and had participated more in geriatric care, and the majority had improvement in their communication skills with elderly patients after taking the Course. Moreover, the graduates are more confident in diagnosing and managing common geriatric problems, and deciding to which specialty to refer the elderly patients. Of the referrals, there was a significant increase to private geriatricians and a significant reduction to other specialists. The average number of elderly patients seen per day had also increased. However, little change was observed about making nursing home visits, the frequency of which remained low. Many graduates expressed difficulties in conducting nursing home visits.

Keywords: continuing medical education, geriatrics, learning outcomes, postgraduate training, primary care doctors 


\section{Introduction}

Population aging is a worldwide phenomenon which arouses great concern among different countries and exerts a heavy burden on the demand for geriatric care (Briggs et al., 2006; Diachun et al., 2006). Subsequently, increasing expectations are put on primary care doctors to shoulder a bigger share of care for patients with common geriatric problems in the community (Hirth et al., 2008). However, not all primary care doctors were adequate to meet these expectations (Turner et al., 2004; Smith et al., 2007), and studies also indicated that undergraduate training in geriatric medicine was insufficient (Keller et al., 2002; Bartram et al., 2006).

In recent years, there emerges a global trend to strengthen the quality of primary care doctors in terms of their medical knowledge and practice through postgraduate studies or vocational training (Pearce et al., 2003; Lam et al., 2006). The effects of postgraduate medical courses on improving health outcomes have aroused much interest (Executive Council, 1998; Illing et al., 2002). Studies in Europe and Australia showed that primary care doctors achieved improvements in clinical practices, patient care, professional role development and lifelong learning interest after taking postgraduate courses (Piterman et al., 2000; Taanila et al. 2002; Schattner et al., 2007). At the same time, barriers to apply their learned skills and concepts into workplace practice were also identified (Pullon et al., 2005).

There is however little information available in the literature on the possible effect of postgraduate training on improving the skills and confidence of primary care doctors in geriatric care (Willett et al., 2007) and the rate of referrals to geriatricians. Moreover, 
knowledge of the impact of postgraduate studies on primary care doctors to participate in community healthcare services for the elderly such as nursing home visits is lacking.

In the wake of a keen concern to strengthen the functions of primary care doctors in geriatric care among the Asian world (WHO, 2004; Flaherty et al., 2007; Food and Health Bureau, 2008; Wang et al., 2010), an evaluative study was conducted to examine the impact of the Postgraduate Diploma in Community Geriatrics (PDCG), which is a one-year part-time programme for primary care doctors developed by the Family Medicine Unit of The University of Hong Kong, in conjunction with the Hong Kong Geriatrics Society. Being a local initiative to enhance geriatric training for its target group, the PDCG includes the components of clinical attachment (20 sessions of clinical geriatric teaching and 5 sessions of rehabilitation and community health services), interactive workshops, locally-developed distance-learning manual, written assignments and examination as well as a clinical examination (detailed course structure and topics of study are shown in Table 1 and Table 2 respectively). Nearly 200 doctors, with the great majority being primary care doctors, have been trained since 2001. The clinical examination adopted the Objective Structure Clinical Examination (OSCE) format from 2006. A Conjoint Clinical Examination for the PDCG and Diploma in Geriatric Medicine (DGM) of the Royal College of Physicians and Surgeons of Glasgow was launched in 2008. This paper describes the outcomes of the PDCG, including impact on clinical skills and patient care, the practice characteristics of the graduates before and after the Course, and the long-term effect upon graduation. 


\section{Methods}

\subsection{Study design}

A questionnaire was developed based on the review of relevant literature and comments from research team members (two senior consultant geriatricians, three senior family physicians and one medical statistician). Likert scale questions and open-ended questions were included to obtain both quantitative and qualitative data that would complement each other. The questionnaire was pilot tested in July 2008 and finalized the following month. A lucky draw (three prizes of US\$60 book coupon each) was conducted amongst all those who had completed and returned their questionnaires as an incentive measure. Ethics approval was obtained from the local Institutional Review Board.

\subsection{Data collection}

Copies of the questionnaire, each enclosed with an invitation letter and a pre-paid return envelope, were sent to doctors who graduated from the PDCG between 2001-2007. The questionnaire itself was anonymous but coded with a reference number to identify the respondent for the lucky draw and for subsequent rounds of reminders. The code was known to one research assistant only and not available to members of the research team.

A total of 188 questionnaires were sent to the PDCG graduates in August 2008. Non-respondents were sent up to two reminders between September and December 2008. To improve the response rate, doctors who had not responded were contacted by telephone after the first reminder. 


\subsection{Data analysis}

Quantitative analysis was carried out using the statistical software SPSS version 17.0. As in most cases, the measurements were mainly made in ordinal scale, statistical inference via the nonparametric Wilcoxon signed rank test on the differences in the responses before and after taking the Course was used to determine if there were significant changes in the median of the differences. A negative value in the median of the differences was an indication that the respondents tended more on the agreed side or a higher number reported after taking the Course. The examination results of the respondents and the non-respondents were also compared using the nonparametric Wilcoxon rank sum test. A two-sided $p$-value $<0.05$ was considered statistically significant. In the sequel, we shall simply quote only the $p$-values and draw conclusions instead of going through the description of testing the null hypothesis that the median of the differences in the responses has not been changed after taking the Course. Moreover, the description in each case would emphasize on the pattern of the differences when the null hypothesis is rejected.

The qualitative responses were analyzed with a grounded theory approach and grouped into common themes independently by TPL and a research assistant who were both experienced in qualitative research. The consistency between the two entries was checked. 


\section{Results}

Of the 188 questionnaires sent to the graduates, one postal address was invalid. Ninety-eight replies were received with a response rate of 52.4\% (98/187). Of the respondents, $78.6 \%$ were male and $21.4 \%$ female, $36.1 \%$ were in public service and the rest in private service. A great majority (91.8\%) of the respondents were primary care doctors, and the remaining few were working in the specialties of Emergency Medicine, Internal Medicine and Nephrology within the hospital setting. The mean (SD) years after graduation from medical school was $14.6(9.48)$. The written and clinical examination results of the respondents and non-respondents were compared using the nonparametric Wilcoxon rank sum test. There were no significant differences (Table 3).

(Table 3 here)

\subsection{The major learning outcomes}

Table 4 shows the major learning outcomes of the students. Nearly all (95.9\%) respondents had modified their approach to elderly patient care after taking the Course. Most respondents felt more rewarding (84.7\%) and had participated more (82.7\%) in geriatric care, and had improvement in their communication skills with elderly patients (79.5\%). However, only 48.9\% indicated that their career opportunities had been enhanced.

(Table 4 here) 


\subsection{Comparison of clinical practice before and after taking the Course}

The responses to this part and the results of Wilcoxon signed rank test are summarized in Table 5 and Table 6.

\subsubsection{Participation in the care of elderly patients}

The average number of elderly patients seen by the respondents per day had increased significantly after taking the course. The median number of elderly patients seen per day was in the range of 11-15 before taking the Course, but had increased to the range of 16-20 after the Course.

Percentages of income contributed by treating elderly patients before and after the Course were compared. There were 55 respondents on a fixed salary and not able to answer this question. Of the 43 respondents who were in private practice, the mean percentage of income contributed by caring for the elderly patients increased slightly from $24.2 \%$ to $27.6 \%$ after taking the Course.

Although the majority of respondents did not make nursing home visit, the proportion of respondents who made these visits increased from $19.8 \%$ to $28.1 \%$ after the Course. Most of them carried out 1-5 nursing home visits per month.

(Table 5 here)

Of the 69 (71.9\%) respondents who did not make any nursing home visit after taking the Course, they rated limited job opportunities (39.1\%) and time constraint (37.7\%) as the 
two main reasons (multiple responses allowed). Only a small percentage of respondents rated lack of secondary/specialist support (14.5\%), relative low remuneration (11.6\%), limited income (5.8\%), not interested (5.8\%), unpleasant working environment (4.3\%) or poor clinical satisfaction (2.9\%) as the reasons.

\subsubsection{Diagnosing and managing geriatric problem}

Before taking the Course, only half of the respondents were confident of diagnosing (55.7\%) and managing (51.6\%) common geriatric problems such as dementia, falls, incontinence and stroke. After taking the Course, most graduates were confident of diagnosing (98.9\%) and managing (93.7\%) these problems.

\subsubsection{Coordination with social support services}

Regarding the coordination of social support services for elderly patients, $66.3 \%$ of the respondents disagreed or strongly disagreed that it was easy for them before taking the Course. This situation reversed upon completion of the Course, with $67.3 \%$ of the respondents felt it easy to coordinate with social support services. However, there was still one-third (32.6\%) of graduates expressing difficulty in this issue.

\subsubsection{Attitudes on geriatric care}

Graduates were asked if they would like to work with chronically ill elderly patients. Significant changes were found after the Course. The combined percentage of 'agree' and 'strongly agree' increased from $68.5 \%$ to $88.5 \%$.

When asked if they hoped caring for elderly patients to be the main part of their practice, 
only half (48.9\%) of the respondents agreed or strongly agreed before taking the Course. The percentage increased to $62.8 \%$ after taking the Course.

\subsubsection{Referral of elderly patients}

The proportion of respondents being confident of deciding to which specialty to refer increased significantly from $73.1 \%$ to $94.6 \%$ after the Course.

(Table 6 here)

Most respondents did not refer elderly patients to private geriatricians, and would refer them to public geriatricians or other specialists. After the Course, the average percentage of elderly patients being referred to private geriatricians increased from $2.8 \%$ to $6.1 \%$, while to other specialists decreased from $53.4 \%$ to $49.1 \%$. The changes in the referrals to private geriatricians and other specialists were statistically significant. However, no significant change was found in the referrals to public geriatricians. The average percentage remained around 44\%. Details of the percentages of referrals are shown in Table 7.

(Table 7 here)

\subsection{Qualitative responses}

The open-ended questions were designed to study the impact of the Course and the barriers to implement what they had learned. The respective responses with corresponding graduation year of the respondents are described below. 
3.3.1. What is the most important impact of the Course on you?

Most responses were related to the increased confidence or knowledge in clinical practices.

Structured program designed specifically for the need of primary care: very useful to improve my daily practice in managing elderly patients. (2001)

Update clinical knowledge especially bedside training that helped increase my confidence. Not just the notes which I can easily find in textbook. (2001)

Some graduates felt that they had increased understanding of the needs of the elderly patients and the social resources available to them.

The management of geriatric medical problems requires a comprehensive and multi-disciplinary approach. The role of family doctor is to coordinate the services provided by various medical specialties. (2002)

3.3.2. Have you experienced any challenges or barriers to implement what you learned in this Course?

The challenges or barriers which the graduates encountered were rather diverse. Time constraint in consultation was one of the main barriers. 
My job nature has limited my care for in-patients/out-patients; not much experience in nursing home care and the time allocated to each patient is very limited, it is difficult to adopt a comprehensive approach to treat each geriatric patient. (2004)

Most elderly patients have multiple and complicated diseases. More consultation time is required. (2005)

There were also problems about expensive drugs or investigations.

Expensive medicine not available in practice; long waiting list for referral to the geriatric team. (2001)

A few respondents expressed that the financial reward to care for elderly patients was limited.

Working hours and financial restraint. (2003)

\section{Discussion}

The year-long postgraduate training course in community geriatrics targeted at primary care doctors is among the very few of this kind of courses in the world. Our results showed that only half of the students were confident of diagnosing (56.7\%) and managing (51.6\%) common geriatric problems such as dementia, falls, incontinence and 
stroke before taking the Course. Compared to the findings of Turner et al. [5] on UK general practitioners’ confidence in the diagnosis (64\%) and management (32\%) of dementia, the PDCG students had lower confidence in diagnosis but higher confidence in management than their UK counterparts. However, after taking the Course, the proportion of graduates being confident of diagnosing (98.8\%) and managing (93.7\%) common geriatric problems had greatly increased.

Most graduates also exhibited greater enthusiasm in geriatric medicine after taking the Course, as indicated by their increased intention to participate in geriatric care and work with chronically ill elderly patients. There was however one-third of graduates who did not want caring for elderly patients to be the main part of their practice after this special training. One possible reason is that primary care doctors generally prefer a wider range of patients and illness conditions in their daily practice (Wright et al., 2004).

Despite a significant increase in the number of elderly patients seen per day, most of our graduates did not make nursing home visit after taking the Course, mainly due to the time constraint and limited job opportunities. Studies done in different parts of the world also offered reasons for the reluctance of many primary care doctors to be involved in this important element of geriatric care. For example, nursing home residents in the UK were found to be associated with higher workload for primary care doctors than other patients of the same age and sex living in the community (Groom et al., 2000). Another UK study showed that English primary care doctors were found to work longer hours if they had a higher proportion of patients in nursing homes (Gravelle et al., 2007). Studies in Australia revealed that many of their primary care doctors found 
visits to nursing home unappealing due to poor level of remuneration for the effort involved (Gadzhanova et al., 2007). As the population is aging, more and more seniors are now residents of nursing homes in Hong Kong. There is a pressing need to promote the participation of primary care doctors in rendering care to the elders residing in nursing homes.

One third of graduates still expressed difficulties in the coordination of social support services for the elderly patients despite the fact that the figure is already much better than before taking the Course that two thirds of them had difficulties. The situation may be aggravated by the complex structure of the current social support services network and government bureaucracy, all of which point to the need of better understanding and closer collaboration between medical and social services.

The proportion of graduates being confident of deciding to which specialty to refer the elderly patients increased from $73.1 \%$ to $94.6 \%$. Of the referrals, there was a statistically significant increase to private geriatricians and a significant reduction to other specialists, but no significant change to public geriatricians was identified after taking the Course. The changes suggest the possibility that the graduates are carrying out their gatekeeping function more effectively. They have improved themselves to recognise those elderly patients who require the attention of specialists more appropriately and make referrals accordingly, and thus reduced the chance of under- or non-treatment of elderly patients, for example, those with cognitive problems (Helmer et al., 2008). Apart from that, graduates are also able to look after more elderly patients with common geriatric problems after taking the Course. This is similar to the finding 
that primary care doctors with an interest or training in a particular specialty may have a higher referral rate in that specialty despite they felt more confident than average in managing problems related to that specialty (O'Donnell et al., 2000; Hermush et al., 2009).

This study has some limitations. The response rate was slightly over 50\% which is not particularly high for this kind of study but already much better than most other surveys among doctors in Hong Kong (The Harvard Team, 1998; Leung et al., 2002; The Hong Kong Medical Association, 2006). However, the examination performance of the respondents is very similar to the non-respondents (Table 3). Hence, our findings should be representative of the study sample. Furthermore, the findings of this study came from the graduates of one postgraduate training course in community geriatrics. All graduates work in the same healthcare system in Hong Kong which is a unique mix of private and public practice. Their educational and clinical needs may also be different from doctors working in other countries. However, as the world's population is aging, especially in more affluent countries, the experience that we have gained in Hong Kong in geriatric education for primary care doctors should be useful to postgraduate medical educators in other countries in meeting the demand of healthcare services for their increasing elderly population.

\section{Conclusion}

The results show that the Course is effective in improving graduates' confidence, attitude and skills in looking after elderly patients with common geriatric disorders. There are significant changes in the practice characteristics of the graduates after taking 
the Course, including the increased number of elderly patients cared for, and improved confidence in making referrals. However, it is also noted that a relatively large proportion of graduates encountered the problems of coordination with social services and conducting nursing home visits.

\section{Conflict of interest}

None.

\section{Acknowledgements}

This study was funded by Committee on Research and Conference Grants of The University of Hong Kong [grant number 200807176094]. The authors would like to thank all those graduates of the Postgraduate Diploma of Community Medicine of the University of Hong Kong for completing the questionnaire. 


\section{References}

Bartram, L., Crome, P., McGrath, A., Corrado, O.J., Allen, S.C., Crome, I., 2006.

Survey of training in geriatric medicine in UK undergraduate medical schools. Age Ageing 35, 533-5.

Briggs, S., Atkins, R., Playfer, J., Corrado, O.J., 2006. Why do doctors choose a career in geriatric medicine? Clin. Med. 6, 469-72.

Department of Health, 2001. National Service Framework for Older People. London: Department of Health.

Diachun, L.L., Hillier, L.M., Stolee, P., 2006. Interest in geriatric medicine in Canada: how can we secure a next generation of geriatricians? J. Am. Geriatr. Soc. 54, $512-9$

Executive Council, The World Federation for Medical Education, 1998. International standards in medical education: assessment and accreditation of medical schools’ educational programmes. A WFME position paper. Med. Educ. 32, 549-58.

Flaherty, J.H., Liu, M.L., Ding, L., Dong, B., Ding, Q., Li, X., Xiao, S., 2007. China: the aging giant. J. Am. Geriatr. Soc. 55, 1295-300.

Food and Health Bureau, 2008. Healthcare Reform Consultation Document "Your health, your life" - Chapter 2: Enhance primary care. Food and Health Bureau. Hong Kong Special Administrative Region Government.

Gadzhanova, S., Reed, R., 2007. Medical services provided by general practitioners in residential aged-care facilities in Australia. Med. J. Aust. 187, 92-4.

Gravelle, H., Hole, A.R., 2007. The work hours of GPs: survey of English GPs. Br. J. Gen. Pract. 57, 96-100.

Groom, L., Avery, A.J., Boot, D., O'Neill, C., Thornhill, K., Brown, K., Jones, R., 2000. 
The impact of nursing home patients on general practitioners' workload. Br. J. Gen. Pract. 50, 473-6.

Helmer, C., Peres, K., Pariente, A., Pasquier, F., Auriacombe, S., Poncet, M., Portet, F., Rouaud, O., Ritchie, K., Tzourio, C., Dartigues, J. F., 2008. Primary and secondary care consultations in elderly demented individuals in France. Results from the Three-City Study. Dement. Geriatr. Cogn. Disord. 26, 407-15.

Hermush, V., Daliot, D., Weiss, A., Brill, S., Beloosesky, Y., 2009. The impact of geriatric consultation on the care of the elders in community clinics. Arch. Gerontol. Geriatr. 49, 260-2.

Hirth, V.A., Eleazer, G.P., Dever-Bumba, M., 2008. A step toward solving the geriatrician shortage. Am. J. Med. 121, 247-51.

Illing, J., Taylor, G.B., O’Halloran, C., 2002. Can a postgraduate course for general practitioners deliver perceived benefit for learners, patients and the NHS?: a qualitative study. Med. Teach. 24, 67-70.

Keller, I., Makipaa, A., Kalenscher, T., Kalache, A., 2002. Global Survey on Geriatrics in the Medical Curriculum. Geneva, WHO.

Lam, T.P., Lam, K.F., Tse, E.Y., 2006. Why do primary care doctors undertake postgraduate diploma studies in a mixed private/public Asian setting? Postgrad. Med. J. 82, 400-3.

Leung, G.M., Ho, L.M., Chan, M.F., Johnston, J.M., Wong, F.K., 2002. The effects of cash and lottery incentives on mailed surveys to physicians. A randomized trial. J. Clin. Epidemiol. 55, 801-807.

O’Halloran, J., Britt, H., Valenti, L., 2007. General practitioner consultations at residential aged-care facilities. Med. J. Aust. 187, 88-91. 
O'Donnell, C.A., 2000. Variation in GP referral rates: what can we learn from the literature? Fam. Pract. 17, 462-71.

Pearce, C., Liaw, S.T., Chondros, P., Piggford, L., McGrath, B., Jones, K., 2003. Australian doctors and their postgraduate qualifications. Aust. Fam. Physician 32, 92-4.

Piterman, L., McCall, L., 2000. Distance education. Part 7. Evaluation of the Graduate Diploma of Family Medicine. Does a distance education course for GPs influence their reported clinical and professional practice? Aust. Fam. Physician, 29, Suppl 1: $38-42$.

Pullon, S., Fry, B., 2005. Interprofessional postgraduate education in primary health care: is it making a difference? J. Interprof. Care 19, 569-78.

The Hong Kong Medical Association, 2006. Report of Doctors’ Fees Survey 2006. Available at: http://www.hkma.org/english/newsroom/newsroom.htm. Assessed 8 Sep 2009.

Schattner, P., Klein, B., Piterman, L., Sturmberg, J., McCall, L., 2007. Impact of Master of Family Medicine degree by distance learning on general practitioners’ career options. Med. Teach. 29, e85-92.

Smith, F., Orrell, M., 2007. Does the patient-centred approach help identify the needs of older people attending primary care? Age Ageing 36, 628-31.

Taanila, A., Larivaara, P., Korpio, A., Kalliokoski, R., 2002. Evaluation of a family-oriented continuing medical education course for general practitioners. Med. Educ. 36, 248-57.

The Harvard Team, 1998. Hong Kong Private Practice Survey, Special Report \#4, Harvard Report. 
Turner, S., Iliffe, S., Downs, M., Wilcock, J., Bryans, M., Levin, E., Keady, J., O'Carroll, R., 2004. General practitioners’ knowledge, confidence and attitudes in the diagnosis and management of dementia. Age Ageing 33, 461-7.

Wang, C. C., Yen, C. H., Liao, W. C., Yuan, S. C., Chen, Y. R., Lee, M. C., Lu, H. J., Bloom, P., 2010. Evaluating outcomes of Taiwan's first gerontology certification program. Arch. Gerontol. Geriatr. 50, 231-240.

Willett, R.M., Boling, P.A., Meyers, M.E., Hoban, J.D., Lawson, S.R., Schlesinger, J.B., 2007. Professional development in geriatrics for community-based generalist faculty. J. Am. Geriatr. Soc. 55, 300-4.

World Health Organization, 2004. WHO Secretariat Report - International Plan of Action on Ageing: report on implementation.WHO.

Wright, B., Scott, I., Woloschuk, W., Brenneis, F., Bradley, J., 2004. Career choice of new medical students at three Canadian universities: family medicine versus specialty medicine. C.M.A.J. 170, 1920-4. 
Table 1 Course structure of PDCG

\begin{tabular}{|lll|}
\hline & $\begin{array}{l}\text { Distance Learning \& Interactive } \\
\text { Workshops }\end{array}$ & Clinical Attachment \\
\hline $\begin{array}{l}\text { Study } \\
\text { Period }\end{array}$ & September - December & $\begin{array}{l}\text { December - June } \\
\text { Once a week, either weekday afternoon } \\
\text { or evening }\end{array}$ \\
& $\begin{array}{l}\text { Designed to enrich students with } \\
\text { theoretical and updated knowledge of } \\
\text { common elderly problems and local } \\
\text { services }\end{array}$ & $\begin{array}{l}\text { Designed to equip students with } \\
\text { practical training in diagnosing and } \\
\text { management skills of common elderly } \\
\text { problems }\end{array}$ \\
& $\begin{array}{l}5 \text { interactive workshops are held on } \\
\text { Saturday afternoons }\end{array}$ & $\begin{array}{l}5 \text { sessions of rehabilitation and } \\
\text { community health services }\end{array}$ \\
& $\begin{array}{l}\text { 10 weeks of locally-developed } \\
\text { distance-learning study }\end{array}$ & 20 sessions of clinical geriatric teaching \\
Assessment & $\begin{array}{l}\text { Written assignments and written } \\
\text { examination }\end{array}$ & Clinical examination \\
\hline
\end{tabular}


Table 2 The study topics of PDCG

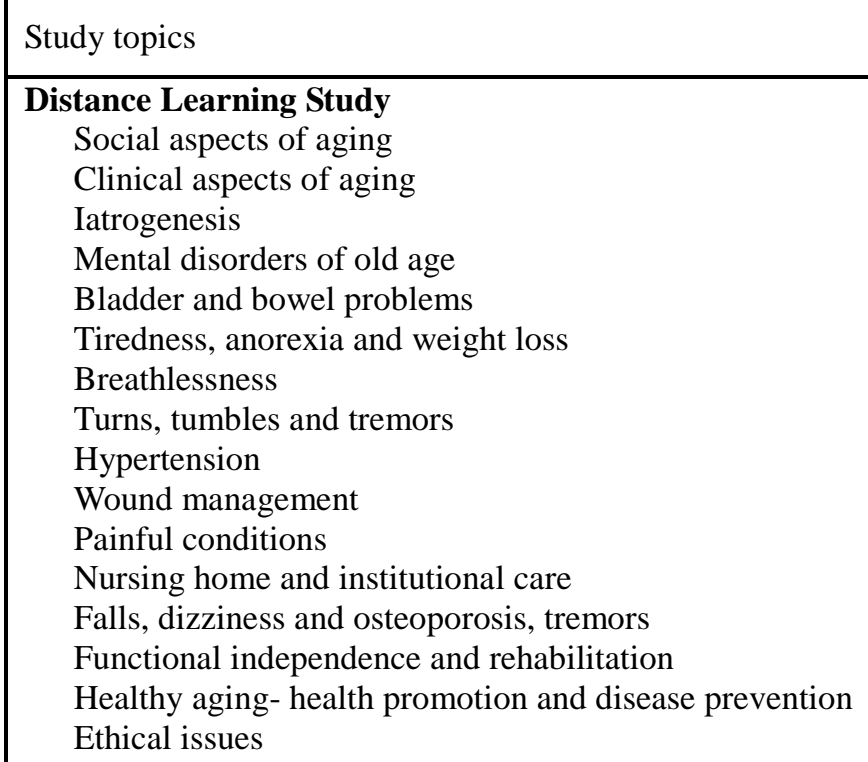

Interactive Workshops (2 seminar topics at each workshop)

Introduction to Geriatric Medicine

Ethical Considerations and Communication Skills in the Care of Elderly People

Use and Abuse of Drugs in Old Age

Geriatric Services in Hong Kong and Community Geriatric Care

Comprehensive Geriatric Assessment and Functional Assessment of Cognitive,

Language, Visual \& Hearing Impairment

Dementia and Delirium

Interpretation of Laboratory Investigations in Elderly People

Common Dermatological Problems in Elderly People

Urinary Incontinence and Constipation in Old Age

Falls and Accidents in Old Age

\section{Clinical Geriatric Teaching}

Stroke

Palliative care in elderly

Pressure sore

Dementia / Cognitive impairment

Diabetes mellitus in elderly

COPD: age related changes

CHF/Hypertension/Cardiac arrhythmia

Sensorium

Rheumatological conditions

Bladder dysfunction

Depression/Anxiety

Instability with recurrent falls

Parkinson disease

Malnutrition

Iatrogenesis and multiple pathology

Social deprivation

Acute confusion in elderly

\section{Clinical Teaching of Rehabilitation and Community Health Services}

Day hospital: allied health services, physiotherapy, occupational therapy, speech therapy and podiatry

Community geriatric assessment team and community nursing services 
Table 3 Comparison of the written and clinical exam results between respondents and non-respondents

\begin{tabular}{|llll|}
\hline & $\begin{array}{l}\text { Respondents } \\
\text { Median }\left(\mathrm{IQR}^{\mathrm{a}}\right), \mathrm{n}\end{array}$ & $\begin{array}{l}\text { Non-respondents } \\
\text { Median (IQR), } \mathrm{n}\end{array}$ & $\begin{array}{l}\text { Wilcoxon } \\
\text { rank-sum test }\end{array}$ \\
\hline $\begin{array}{l}\text { Written exam } \\
\text { (total mark = 100) }\end{array}$ & $\begin{array}{l}65.60(62.48-69.50), \\
\mathrm{n}=98\end{array}$ & $\begin{array}{l}64.65(60.85-69.43), \\
\mathrm{n}=90\end{array}$ & $p=0.144$ \\
$\begin{array}{l}\text { Clinical exam 2001-2006 } \\
\text { total mark = 100) }\end{array}$ & $\begin{array}{l}60.75(56.95-65.18), \\
\mathrm{n}=74\end{array}$ & $\begin{array}{l}59.40(54.48-63.23), \\
\mathrm{n}=66\end{array}$ & $p=0.088$ \\
$\begin{array}{l}\text { Clinical exam after 2006 } \\
\begin{array}{l}\text { (OSCE format } \\
\text { total mark }=32)\end{array}\end{array}$ & $\begin{array}{l}26.50(24.63-28.50), \\
\mathrm{n}=24\end{array}$ & $\begin{array}{l}27.00(25.13-29.00), \\
\mathrm{n}=24\end{array}$ & $p=0.508$ \\
\hline
\end{tabular}

${ }^{a}$ Interquartile range

${ }^{\mathrm{b}}$ The clinical examination adopted the Objective Structure Clinical Examination (OSCE) format from 2006 
Table 4 The major learning outcomes (in descending order of combined frequencies of Likert scales 3 and 4)

\begin{tabular}{|c|c|c|c|c|}
\hline As a result of the course ... & $\begin{array}{c}\text { strongly } \\
\text { disagree } \\
1\end{array}$ & $\begin{array}{l}\text { disagree } \\
2\end{array}$ & $\begin{array}{c}\text { agree } \\
3\end{array}$ & $\begin{array}{c}\text { strongly } \\
\text { agree }^{\mathrm{a}} \\
4\end{array}$ \\
\hline $\begin{array}{l}\text { I have modified my approach to elderly patient } \\
\text { care }\end{array}$ & $0(0.0 \%)$ & $4(4.1 \%)$ & $66(67.3 \%)$ & $28(28.6 \%)$ \\
\hline I have found it more rewarding in geriatric care & $0(0.0 \%)$ & $15(15.3 \%)$ & $68(69.4 \%)$ & $15(15.3 \%)$ \\
\hline I have participated more in geriatric care & $0(0.0 \%)$ & $17(17.3 \%)$ & $57(58.2 \%)$ & $24(24.5 \%)$ \\
\hline $\begin{array}{l}\text { I have improved my communication skills with } \\
\text { elderly patients }\end{array}$ & $0(0.0 \%)$ & $20(20.4 \%)$ & $56(57.1 \%)$ & $22(22.4 \%)$ \\
\hline $\begin{array}{l}\text { I have increased my interest in lifelong learning } \\
\text { through additional training }\end{array}$ & $2(2.0 \%)$ & $30(30.6 \%)$ & $56(57.1 \%)$ & $10(10.2 \%)$ \\
\hline $\begin{array}{l}\text { I have increased my interest in pursuing other } \\
\text { postgraduate studies }\end{array}$ & $0(0.0 \%)$ & $50(51.0 \%)$ & $40(40.8 \%)$ & $8(8.2 \%)$ \\
\hline My career opportunities have enhanced & $2(2.0 \%)$ & $48(49.0 \%)$ & $41(41.8 \%)$ & $7(7.1 \%)$ \\
\hline
\end{tabular}

${ }^{\mathrm{a}}$ Likert scale from 1 (strongly disagree) to 4 (strongly agree). Percentages on valid data across rows of the table 
Table 5 Changes in participation in the care of elderly patients

\begin{tabular}{|c|c|c|c|}
\hline & Pre-course & Post-course $^{\mathrm{a}}$ & $\begin{array}{c}\text { Wilcoxon } \\
\text { signed } \\
\text { rank test }\end{array}$ \\
\hline \multicolumn{4}{|c|}{ Elderly patients (age over 65 ) seen per day $(n=98)$} \\
\hline $0-5$ & $19(19.4 \%)$ & $14(14.3 \%)$ & \multirow{5}{*}{$\begin{aligned} Z & =-2.145 \\
p & =0.032\end{aligned}$} \\
\hline $6-10$ & 17 (17.3\%) & 21 (21.4\%) & \\
\hline $11-15$ & $15(15.3 \%)$ & $11(11.2 \%)$ & \\
\hline $16-20$ & $8(8.2 \%)$ & 15 (15.3\%) & \\
\hline Over 20 & 39 (39.8\%) & 37 (37.8\%) & \\
\hline \multicolumn{4}{|c|}{$\begin{array}{l}\text { Percentage of income contributed by looking } \\
\text { after elderly patients }(n=43)\end{array}$} \\
\hline $0-10$ & 15 (34.9\%) & $10(23.3 \%)$ & \multirow{6}{*}{$\begin{aligned} Z & =-3.667 \\
p & <0.001\end{aligned}$} \\
\hline $11-20$ & 13 (30.2\%) & $16(37.2 \%)$ & \\
\hline $21-30$ & $7(16.3 \%)$ & $6(14.0 \%)$ & \\
\hline $31-40$ & $2(4.7 \%)$ & $3(7.0 \%)$ & \\
\hline $41-50$ & $3(7.0 \%)$ & $4(9.3 \%)$ & \\
\hline Over 50 & $3(7.0 \%)$ & $4(9.3 \%)$ & \\
\hline \multicolumn{4}{|c|}{$\begin{array}{l}\text { Number of nursing home visits made per month } \\
(n=96)\end{array}$} \\
\hline Nil & 77 (80.2\%) & 69 (71.9\%) & \multirow{5}{*}{$\begin{array}{l}Z=-2.581 \\
p=0.010\end{array}$} \\
\hline $1-5$ & $16(16.7 \%)$ & 19 (19.8\%) & \\
\hline $6-10$ & $2(2.1 \%)$ & $6(6.3 \%)$ & \\
\hline $11-15$ & $0(0.0 \%)$ & $0(0.0 \%)$ & \\
\hline Over 15 & $1(1.0 \%)$ & $2(2.1 \%)$ & \\
\hline
\end{tabular}

${ }^{a}$ Percentages refer to valid responses only. The whole pair of responses would be excluded in the analysis if either the response to pre- or post-course was missing. 
Table 6 Changes in confidence and attitude in the care of elderly patients

\begin{tabular}{|c|c|c|c|}
\hline & Pre-course & Post-course $^{\mathrm{a}}$ & $\begin{array}{l}\text { Wilcoxon } \\
\text { signed } \\
\text { rank test }\end{array}$ \\
\hline \multicolumn{4}{|c|}{$\begin{array}{l}\text { I am confident of diagnosing patients with } \\
\text { common geriatric problems (e.g. dementia, falls, } \\
\text { incontinence, stroke) }(n=88)\end{array}$} \\
\hline Strongly disagree & $3(3.4 \%)$ & $0(0.0 \%)$ & \multirow{4}{*}{$\begin{array}{c}Z=-7.280 \\
p<0.001\end{array}$} \\
\hline Disagree & 36 (40.9\%) & $1(1.1 \%)$ & \\
\hline Agree & 47 (53.4\%) & 59 (67.0\%) & \\
\hline Strongly agree & $2(2.3 \%)$ & 28 (31.8\%) & \\
\hline \multicolumn{4}{|c|}{$\begin{array}{l}\text { I am confident of managing common geriatric } \\
\text { disorders }(n=95)\end{array}$} \\
\hline Strongly disagree & $3(3.2 \%)$ & $1(1.1 \%)$ & \multirow{4}{*}{$\begin{array}{c}Z=-7.924 \\
p<0.001\end{array}$} \\
\hline Disagree & $43(45.3 \%)$ & $5(5.3 \%)$ & \\
\hline Agree & 48 (50.5\%) & $58(61.1 \%)$ & \\
\hline Strongly agree & $1(1.1 \%)$ & 31 (32.6\%) & \\
\hline \multicolumn{4}{|c|}{$\begin{array}{l}\text { I can coordinate easily with social support } \\
\text { services for elderly patients }(n=95)\end{array}$} \\
\hline Strongly disagree & $6(6.3 \%)$ & $2(2.1 \%)$ & \multirow{4}{*}{$\begin{array}{c}Z=-6.087 \\
p<0.001\end{array}$} \\
\hline Disagree & 57 (60.0\%) & 29 (30.5\%) & \\
\hline Agree & $30(31.6 \%)$ & 54 (56.8\%) & \\
\hline Strongly agree & $2(2.1 \%)$ & 10 (10.5\%) & \\
\hline \multicolumn{4}{|c|}{$\begin{array}{l}\text { I would like to work with chronically ill elderly } \\
\text { patients }(n=95)\end{array}$} \\
\hline Strongly disagree & $2(2.1 \%)$ & $1(1.1 \%)$ & \multirow{4}{*}{$\begin{array}{r}Z=-5.905 \\
p<0.001\end{array}$} \\
\hline Disagree & 28 (29.5\%) & $9(9.5 \%)$ & \\
\hline Agree & $62(65.3 \%)$ & $60(63.2 \%)$ & \\
\hline Strongly agree & $3(3.2 \%)$ & 25 (26.3\%) & \\
\hline \multicolumn{4}{|c|}{$\begin{array}{l}\text { I hope caring for elderly patients to be the main } \\
\text { part of my practice }(n=94)\end{array}$} \\
\hline Strongly disagree & 5 (5.3\%) & 3 (3.2\%) & \multirow{4}{*}{$\begin{array}{c}Z=-4.300 \\
p<0.001\end{array}$} \\
\hline Disagree & $43(45.7 \%)$ & 32 (34.0\%) & \\
\hline Agree & $44(46.8 \%)$ & $50(53.2 \%)$ & \\
\hline Strongly agree & $2(2.1 \%)$ & $9(9.6 \%)$ & \\
\hline \multicolumn{4}{|c|}{$\begin{array}{l}\text { I am confident of deciding which specialty to refer } \\
\text { an elderly patient to if a referral is necessary } \\
(n=93)\end{array}$} \\
\hline Strongly disagree & $1(1.1 \%)$ & $2(2.2 \%)$ & \multirow{4}{*}{$\begin{array}{l}Z=-6.451 \\
p<0.001\end{array}$} \\
\hline Disagree & $24(25.8 \%)$ & $3(3.2 \%)$ & \\
\hline Agree & $63(67.7 \%)$ & 55 (59.1\%) & \\
\hline Strongly agree & $5(5.4 \%)$ & 33 (35.5\%) & \\
\hline
\end{tabular}

${ }^{a}$ Percentages refer to valid responses only. The whole pair of responses would be excluded in the analysis if either the response to pre- or post-course was missing. 
Table 7 Percentages of referrals to private geriatricians, public geriatricians and other specialists.

\begin{tabular}{|c|c|c|c|}
\hline $\begin{array}{l}\text { Percentage of elderly patients who had } \\
\text { specialist referrals were referred to... }\end{array}$ & Pre-course & Post-course & $\begin{array}{c}\text { Wilcoxon } \\
\text { signed rank } \\
\text { test }\end{array}$ \\
\hline \multicolumn{4}{|l|}{ Private geriatricians } \\
\hline 0 & $61(88.4 \%)$ & 55 (79.7\%) & \multirow{6}{*}{$\begin{array}{c}Z=-2.558 \\
p=0.011\end{array}$} \\
\hline $1-20$ & $6(8.7 \%)$ & $9(13.0 \%)$ & \\
\hline $21-40$ & $1(1.4 \%)$ & $1(1.4 \%)$ & \\
\hline $41-60$ & $0(0.0 \%)$ & $2(2.9 \%)$ & \\
\hline $61-80$ & $0(0.0 \%)$ & $0(0.0 \%)$ & \\
\hline $81-100$ & $1(1.4 \%)$ & $2(2.8 \%)$ & \\
\hline \multicolumn{4}{|l|}{ Public geriatricians } \\
\hline 0 & $10(14.5 \%)$ & $5(7.2 \%)$ & \multirow{6}{*}{$\begin{array}{c}Z=-0.748 \\
p=0.455\end{array}$} \\
\hline $1-20$ & $20(28.8 \%)$ & 25 (36.2\%) & \\
\hline $21-40$ & $8(11.6 \%)$ & $6(8.7 \%)$ & \\
\hline $41-60$ & $8(11.6 \%)$ & $12(17.4 \%)$ & \\
\hline $61-80$ & $6(8.7 \%)$ & $8(11.6 \%)$ & \\
\hline $81-100$ & 17 (24.6\%) & 13 (18.8\%) & \\
\hline \multicolumn{4}{|l|}{ Other specialists } \\
\hline 0 & $16(23.2 \%)$ & 14 (20.3\%) & \multirow{6}{*}{$\begin{array}{l}Z=2.116 \\
p=0.034\end{array}$} \\
\hline $1-20$ & $6(8.7 \%)$ & 8 (11.6\%) & \\
\hline $21-40$ & $7(10.1 \%)$ & $9(13.0 \%)$ & \\
\hline $41-60$ & $5(7.2 \%)$ & 11 (15.9\%) & \\
\hline $61-80$ & $12(17.4 \%)$ & 10 (14.5\%) & \\
\hline $81-100$ & $23(33.3 \%)$ & 17 (24.6\%) & \\
\hline
\end{tabular}

